\title{
Noise Removal and QRS Detection of ECG Signal
}

\author{
Jannatul Robaiat Mou ${ }^{1}$, Sheikh Md. Rabiul Islam¹, Xu Huang ${ }^{2}$ and Keng Liang Ou ${ }^{3}$ \\ ${ }^{1}$ Dept. of Electronics and Communication Engineering \\ Khulna University of Engineering \&Technology, Bangladesh. \\ ${ }^{2}$ Faculty of ESTEM, University of Canberra, Australia, \\ ${ }^{3}$ College of Oral Medicine, Taipei Medical, University, Taiwan. \\ jannatulruet@gmail.com; robi@ece.kuet,ac.bd; Xu.Huang@canberra.edu.au, klou@tmu.edu.tw
}

\begin{abstract}
In electrocardiogram (ECG), noise removal and QRS complex play the vital role for detecting various heart diseases. So, noise free and accurate QRS detection becomes very important in ECG signal. In this paper we are going to describe a new algorithms which are able to make it noise free and detect QRS complex in ECG signal. Generally, a noise free algorithm removes the noisy signal and we have used Remez exchange algorithm for 1st algorithm, designed an arbitrary magnitude with FIR filter for 2nd algorithm and FIR filter with window method for 3rd proposed algorithms. The noise free ECG signal of QRS complex can be detected by proposed detection algorithms. The performance parameters are SNR, PRD, MSE and Correlation and accuracy, sensitivity, specificity, precision are used to justify the proposed noise free algorithm and QRS detection. The real data examples and experimental results approve new algorithms which are more effective in ECG applications.
\end{abstract}

Keywords-ECG, QRS complex, Threshold, SNR, PRD.

\section{Introduction}

Electrocardiogram (ECG) is the recording of electrical activity of the heart and used to investigate the heart diseases. Due to its non-invasive nature it is a most popular diagnostic tool. This is done by measuring the potential difference between several electrodes which are placed on the skin at predefined points of the human body [1]. ECG is a graphical representation of heart based on electrical impulses. This graphical or recording is for the case of chest pain occurred such as heart attack, rapidity of breath, faster heartbeats, high blood pressure, high cholesterol and to check the heart's electrical activity [21]. Mostly ECG recording is very sensitive and its affects by different types of noise and its change the amplitude and duration of the signal. In literature review that mostly ECG signals are affected by white noise, colored noise, electrode movement noise, muscle artifact noise, baseline wander, composite noise, electromyographic (EMG) noise, abrupt noise and power line interference [21], [25]. These noise creates more complicated for diagnosis of the ECG signal. Many researcher, find out the problem statement of noises. Some of the authors have solved this problem by proposed different algorithm for remove of noise [23], [24], [25]. The authors [24], proposed algorithm based on linear FIR filter with Recursive Running Sum (RRS) filters. They have considered 50 or $60 \mathrm{HZ}$ power line noise for a high resolution ECG signal sampling at $600 \mathrm{~Hz}$. This algorithm have shown low resolution smooth signal. In [21], the authors were found the performance of 
adaptive NLMS filter better than adaptive LMS filter. But in practical way, the performance parameters have shown lowest values than others. The proposed algorithm with DWT in [22] have shown good results based on WGN noise and Poisson noise. They didn't justify of this algorithm based on performance parameters. The authors [26] were proposed enhanced adaptive impulsive noise cancellation technique using State Space Recursive Least Square (SSRLS) algorithm based. This algorithm is used only MSE for performance of proposed algorithm and shown lowest results than others.

ECG consists of three wave components and they are P wave, QRS complex and T wave. The most important part of ECG signal is QRS complex because heart beat detection depends on it. QRS complex of ECG signal can be definitely distinguished from $P$ wave and T wave because of its high amplitude and peak with long time span as in Figure 1. Many researchers have developed methodology or algorithm for the use of R peak / QRS complex detection. The peak detection difficulties occur when the input electrical signal is disrupted by unwanted noise and interference [9]. Mohamed Elgendi is improved QRS detection algorithm using dynamic thresholds [2]. Jiapu Pan developed an algorithm for QRS detection which was based on slope, amplitude, and width [3]. Ren-guey lee developed a new QRS detection algorithm. This algorithm is enhanced the accuracy of R wave detection by reverse R wave [4]. They have not shown other detection parameter values such as sensitivity, specification, precision. Q. Xue, developed a neuralnetwork-based adaptive matched filtering for QRS detection [5]. In reference [6], V.S. Chouhan developed a methodology to detect of QRS complexes in 12-lead ECG using adaptive quantized. Form this methodology or algorithms, there are some lack of novelty work. We are tried to find the problem statement of ECG diagnosis. The most important effect of ECG noise and detection. In this research work we are going to propose few new algorithms for noise free ECG signal and then proposed detection algorithm which will detect a QRS complex and for simplicity we are ignoring P wave and T wave.

This paper is structured as follows. Section 2 describes the proposed methodology for noise free. Section 3 describes new algorithm for QRS detection. Section 4 describes performance measurements for evaluation of signal. Section 5 demonstrates the simulation result \& discussion. Finally in Section 6 , a conclusion is presented.

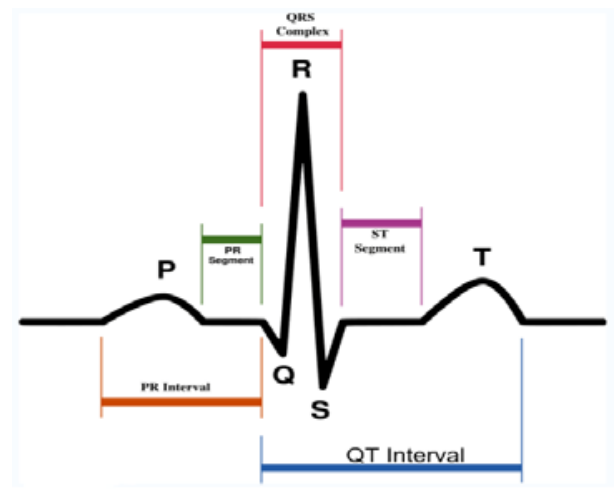

Figure 1. An example of ECG signal.

\section{Noise Elimination Methodology}

We have proposed some algorithm for noise elimination of ECG signal which is described as below: 


\subsection{Algorithm-1}

We have described an algorithm based on linear phase FIR low pass filter using Remez exchange algorithm [9] as below:

1. To design linear phase FIR low pass filters using Remez exchange algorithm required to satisfy the following specifications:

\begin{tabular}{|l|l|}
\hline Passband & $0-900 \mathrm{~Hz}$ \\
\hline Passband ripple & $3 \mathrm{~dB}$ \\
\hline Stopband ripple & $40 \mathrm{~dB}$ \\
\hline Cutoff frequency & $900-1000 \mathrm{~Hz}$ \\
\hline Sampling frequency & $2000 \mathrm{~Hz}$ \\
\hline
\end{tabular}

2. Normalized each band edge frequency by sampling frequency and transition width.

3. Estimate of filter length can be determined by using Remez exchange algorithm [9]. This require by need to calculate of passband and stopband deviation by [9]:

$$
\delta_{p}=2 \times \frac{10^{\frac{A_{p}}{20}}-1}{10^{\frac{A_{p}}{20}}+1}, \delta_{s}=10^{-\frac{A_{s}}{20}}
$$

Where $A_{p}$ and $A_{s}$ are the passband and stopband ripples respectively, in $\mathrm{dB}$.

4. The input parameters are setting for optimal design program to obtain the coefficients of filter length and band edge frequencies.

5. Check the pass band ripple and stop band attenuation produced by program

6. If the specifications are not satisfied, repeat the procedure of step 4 and 5.

7. Find the out the impulse response or filter coefficients and apply to noisy ECG signal and get ECG filtered signal.

\subsection{Algorithm-2}

Design of FIR filter with arbitrary magnitude response:

1. A prerequisite FIR filter that the desired frequency response $(H(k))$ characteristics depicted as specified requirements:

\begin{tabular}{|l|l|}
\hline Passband frequency 1 & $0-150 \mathrm{~Hz}$ \\
\hline Transition Band frequency 1 & $150-250 \mathrm{~Hz}$ \\
\hline Passband frequency 2 & $250-450 \mathrm{~Hz}$ \\
\hline Transition Band frequency 2 & $450-500 \mathrm{~Hz}$ \\
\hline Passband frequency 3 & $500-750 \mathrm{~Hz}$ \\
\hline Transition Band frequency 3 & $750-850 \mathrm{~Hz}$ \\
\hline Stopband frequency & $850-1000 \mathrm{~Hz}$ \\
\hline Passband ripple & $0 \mathrm{~dB}$ \\
\hline Stopband ripple & $0 \mathrm{~dB}$ \\
\hline
\end{tabular}

2. Assume sampling frequency $2 \mathrm{KHz}$ and filter length $\mathrm{N}=10$.

3. From the specification can be design tables as 
Journal of Biomedical Engineering and Medical Imaging, Volume 3, No. 4, Aug 2016

\begin{tabular}{|c|c|c|c|c|c|c|c|c|}
\hline $\begin{array}{c}\text { Frequency sampling } \\
\text { point }\left(f_{d}\right)\end{array}$ & 0 & 0.15 & 0.25 & 0.45 & 0.5 & 0.75 & 0.85 & 1 \\
\hline $\begin{array}{c}\text { Frequency sample } \\
(H(k))\end{array}$ & 1 & 1 & 0.6 & 0.6 & 0.1 & 0.1 & 0 & 0 \\
\hline
\end{tabular}

4. The impulse response or filter coefficients $h(n)$ can be obtained as the inverse DFT of the frequency sample $h(n)=\frac{1}{N} \sum_{k=0}^{N-1} H(k) e^{j(2 \pi / N) n k}$ where $H(k), k=0,1, \ldots, N-1$ samples of the ideal or target frequency response are.

5. The impulse response $h(n)$ coefficients is applied to noisy ECG signal to find the filtered ECG signal.

\subsection{Algorithm-3}

Design an FIR low pass filter using window method to remove noise from signal and its algorithm is described as:

1. Specifying an FIR filter design of a low pass filter $H_{d}(w)= \begin{cases}1, & |\omega|<\frac{\pi}{4} \\ 0, \text { otherwise }\end{cases}$

2. Obtained the desired response $h_{D}(n)$ from the $H_{d}(w)$ as like

3. $h_{d}(n)=\left\{\begin{array}{c}2 f_{c} \frac{\operatorname{sinc}\left(n \omega_{c}\right)}{n \omega_{c}}, n=1,2, \ldots . M-1 \\ 2 f_{c}, n=0\end{array}\right.$

4. Select a window function $w(n)$ (such as Rectangular, Hamming, Hanning, Blackman, and Kaiser [9]) that satisfies the passband or stopband attenuation.

5. Assume the filter length $M=10$.

6. Obtained values of $w(n)$ for chosen window function and the values of the actual FIR filter coefficients by $h(n)=h_{d}(n) * w(n)$.

7. Apply filter coefficients $h(n)$ to the ECG noisy signal and remove unwanted signal and get smoothed ECG signal.

\section{QRS Detection Methodology}

The proposed QRS complex of ECG signal detection algorithm is summarized as Algorithm-4:

1. Introduce ECG signals from ECG database.

2. Perform the different noises (i.e., power line interference, Baseline wonder, EMG, abrupt noise) individual into the original ECG signal.

3. Filtered of ECG noisy signal by using Algorithm-1, Algorithm-2, and Algorithm-3 respectively.

4. Detection of QRS :

5. Apply proposed threshold $(T)$ on ECG signal

$$
T=\frac{1}{N} \sum_{i=1}^{N} x_{e c g_{i}^{2}} .
$$


where $x_{e c g}$ is the raw ECG signal and $\mathrm{N}$ vectors of $x_{e c g_{i}}, i \in\{1,2, \ldots \ldots N\}$ of signal samples numbers.

With proposed threshold $(T)$, QRS detection is calculated by

$$
\hat{x}_{e c g}=\left\{\begin{array}{c}
x_{e c g} \text { for } x_{e c g} \geq T \\
0 \text { for } x_{e c g}<T
\end{array}\right.
$$

6. Repeat procedures:

Input:

$i$ : present sample value,

$i-1$ : past sample value,

$i+1$ : future sample value

Assume detect position and values are zero, i.e.,

$R_{p}=0, Q_{p}=0, S_{p}=0, R_{v}=0, Q_{v}=0, S_{v}=0$.

// First find out the $R$-wave positions and values:

Old difference $=\left(\hat{x}_{e c g}(\mathrm{i}-1)-\hat{x}_{e c g}(i)\right)$;

New difference $=\left(\hat{x}_{e c g}(\mathrm{i})-\hat{x}_{e c g}(i+1)\right)$;

For $i=1$ : length $\left(x_{\text {ecg }}\right)$

if (Old difference $<0 \& \&$ New difference $>0$ )

$$
\begin{aligned}
R_{p} & =\left[\begin{array}{ll}
R_{p} \mathrm{i}
\end{array}\right] ; \\
R_{v} & =\left[\begin{array}{ll}
R_{v} & \hat{x}_{e c g}(\mathrm{i})
\end{array}\right] ;
\end{aligned}
$$

else continue;

// First find out the $Q$-wave positions and values:

$Q=i-1$;

while (Old difference <0)

Old difference $=\left(\widehat{(x}_{e c g}(Q-1)-\hat{x}_{e c g}(Q)\right)$;

$$
Q=Q-1
$$

end

$Q_{p}=\left[\begin{array}{ll}Q_{p} & \mathrm{Q}\end{array}\right]$;

$Q_{v}=\left[\begin{array}{ll}Q_{v} & \hat{x}_{e c g}(\mathrm{Q})\end{array}\right]$;

// First find out the S-wave positions and values:

$\mathrm{S}=\mathrm{i}+1$;

while (New difference $>0$ )

$$
\begin{aligned}
& \text { New difference }=\left(\hat{x}_{e c g}(\mathrm{~S})-\hat{x}_{e c g}(\mathrm{~S}+1)\right) \\
& S=S+1
\end{aligned}
$$

end

$S_{p}=\left[S_{p}-S\right]$

$S_{p}=\left[\begin{array}{ll}S_{p} & \left.\hat{x}_{e c g}(\mathrm{~S})\right] ;\end{array}\right.$ 
end

end

7. Finally store and detect of QRS position and values.

8. Output: QRS detection from ECG signal

9. Until there is no further successive ECG signal.

10. Performance test based on accuracy, sensitivity, specification, precision.

11. Compare this algorithm with conventional algorithm.

\section{Performance Assessments}

Many literature review have studies about the performance assessment of reconstructed signal and original signal and their comparative evaluation [27]. Some of performance parameter are described below that were used in this research work.

\subsection{Signal to Noise ratio:}

The signal-to-noise ratio can be defined as

$$
S N R_{\text {ecg }}=\frac{\frac{1}{N} \sum_{i=1}^{N} x_{\text {ecg }}^{2}}{\frac{1}{N} \sum_{i=1}^{N} x_{\text {ecg }}^{2}-\frac{1}{N} \sum_{i=1}^{N} x_{\text {Denoised_ecg }}^{2}}
$$

Where $S N R=10 \log _{10} S N R_{\text {ecg }} d B$ and $x_{\text {Denoised_ecg }}$ is the filtered ECG signal.

\subsection{Mean Square Error:}

It is measured between the original ECG signal and filtered ECG signal. It can be defined as

$$
M S E=\frac{1}{N} \sum_{i=1}^{N}\left[x_{\text {ecg }}^{2}-x_{\text {Denoised_ecg }}^{2}\right]
$$

\subsection{Percentage root-mean-square difference (PRD):}

It can be defined as:

$$
P R D=\sqrt{\frac{\sum_{i=1}^{N}\left[x_{\text {ecg }}^{2}-x_{\text {Denoised_ec }}^{2}\right]}{\frac{1}{N} \sum_{i=1}^{N} x_{\text {ecg }}^{2}}} \times 100
$$

\subsection{Correlation:}

The discrete autocorrelation between the two signal $x$ and $y$ is defined as

$$
r_{x x}=\frac{1}{N} \sum_{k=1}^{N} x_{e c g}[n] x_{e c g}[n+k]
$$

and the cross correlation is 


$$
r_{x y}=\frac{1}{N} \sum_{k=1}^{N} x_{\text {Denoised_ecg }}[n] x_{\text {ecg }}[n+k]
$$

The correlation coefficient $(r)$ is measured between two numerical variables or signals for paired observations. If the correlation coefficient is normalized, its absolute value will range from 0 to 1 , making it easier to judge the similarity between the signals. If the normalized correlation coefficient is equal to either 1 or -1 , the two signals are perfectly correlated. If $r$ value is close to +1 indicates a perfect positive fit or positive relationship between the two signal $x$ and $y$ i.e., the values of $x$ increases, the values of $y$ also increases. If $r$ value is close to -1 indicates a perfect negative fit. If $r$ value is close to 0 , there is no relationship between $x$ and $y$.

\subsection{Power Spectral Density:}

We have investigated three methods for power spectral estimation (PSD) such as non-parametric methods such as Periodogram, Welch and Lomb-Scargle algorithm [27]. Lomb-Scargle algorithm can compute spectra of nonuniformly sampled signals or signals with missing samples.

Taking Fourier transform of autocorrelation equation results are an estimate of power spectrum [27]:

$$
P\left(e^{j \omega}\right)=\sum_{n=-N+1}^{N-1} r_{x x} e^{-j \omega n}
$$

is called Periodogram.

Consider, an $\mathrm{N}$ point data ECG sequence is partition as $x[n], 0 \leq n \leq N-1$, into $L$ segments of $M$ samples each thesegments $x_{M}^{l}[n]$ are formed we have $N \gg L M$. Thus,

$$
x_{M}^{l}[n]=x[n+l M-M]\left\{\begin{array}{c}
0 \leq n \leq M-1 \\
1 \leq l \leq L
\end{array}\right.
$$

For estimate of Welch PSD computation of $L$ periodograms

$$
P_{M}^{l}\left(e^{j \omega}\right)=\frac{1}{W}\left|\frac{1}{N} \sum_{n=0}^{N-1} x_{M}^{l}[n] e^{-j \omega k}\right|^{2}, 1 \leq l \leq M
$$

where $W=\sum_{l=1}^{M} \boldsymbol{w}^{2}(l)$ and $\boldsymbol{w}(\boldsymbol{l})$ is window function. This is the Welch method of PSD.

\section{Simulation Results}

The ECG dataset used in this research work are collected from the MIT/BIH Arrhythmia Database [7]. In Figure 2(a), (b), we have plotted the raw ECG signal and noisy ECG signal. We have considered different noises such as power line interference, baseline wonder and EMG and abrupt noise. For power line interference and baseline wonder, we have considered $50 \mathrm{~Hz}$ noise frequency and $0.5 \mathrm{mV}$ amplitude for added into ECG signal. This electromyography (EMG) noise is simulated by adding random noise to the ECG. Array of random numbers was created consisting of values of \pm 0.50 of the ECG maximum amplitude to the uncorrupted ECG. The reduced noise levels are formed by scaling the random numbers by the appropriate amount. For abrupt shift noise random numbers (within $\pm 0.5 \mathrm{mV}$ ) were generated, but the same random number was taken for $500 \mathrm{~ms}$ duration cycle and then another random number was 
generated for next cycle and so on. All of these noises are filtered by Algorithm-1, Algorithm-2, and Algorithm-3 respectively. Figure 2(c) shows the ECG filtered signal by using Algorithm -1, Figure 2(d) shows ECG filtered signal by Algorithm-2 where Figure 3 has shown the desired frequency response for filter operations. Figure 2(e) shows the noise removed from ECG signal after applied Algorithm-3 where we have used Hanning window. To measure the performance for different noise removal methods, the distortion between original signal and reconstructed signal is measured by mean square error (MSE), signal-to-noise ratio (SNR), percentage root-mean-square difference (PRD), and correlation coefficients values. In Table I-IV have shown the results of correlation values, SNR, MSE and percentage root-meansquare difference (PRD). The proposed Algorithm-1, \& 3 have acquired highest SNR, and lowest MSE, PRD and also good correlation coefficients values than Algorithm-2 \& 3. The Algorithm -1 is achieve 9.0202 for SNR, 0.0395 for MSE, 40.65 for PRD and 0.9912 for correlation on an average value in MIT-BIH database as shown in Table I-IV for power line interference and base interference noise. However, the case of EMG and abrupt noise, the values of SNR, MSE, PRD and Correlation value are slightly difference than power line interference and base interference noise. We have checked that the correlation coefficients value $(r)$, if $r>0.8$ is generally described as strong, whereas $r<0.5$ is generally described as weak in MIT-BIH database. In Table I, Algorithm-1 shows strong correlation value $(r \approx 1)$ whereas Algorithm-2 \& Algorithm -3 also shows positive and strong correlation value $(r \approx 0.76)$ and $(r \approx 0.64)$ for all noises. However, in visual representation, Figures 2(c) - (e), the Algorithm 2 and 3 have shown good smoothed ECG signal as compared to Algorithm-1.In this figure we have consider only EMG noise. In Table II shows Algorithm-1 is achieved the highest SNR value (SNR = 10 (on average)) than the Algorithm-2 and 3. Table III and IV shows Algorithm-1 achieves 0.03 for MSE and $41 \%$ for PDR which is the lowest than Algorithm-2 and 3. 
Jannatul Robaiat Mou, Sheikh Md. Rabiul Islam, Xu Huang and Keng Liang Ou; Noise Removal and QRS Detection of ECG Signal. Journal of Biomedical Engineering and Medical Imaging, Volume 3, No 4, August (2016), pp 1-17
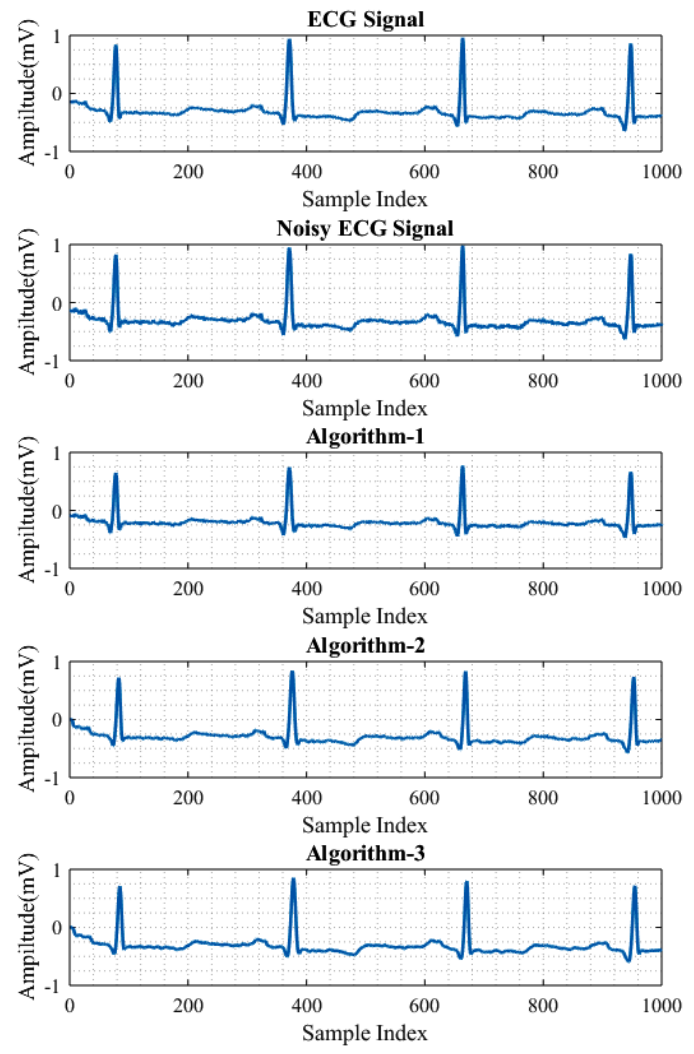

Figure 2. The raw ECG signal collected from MIT/BIH Arrhythmia Database.

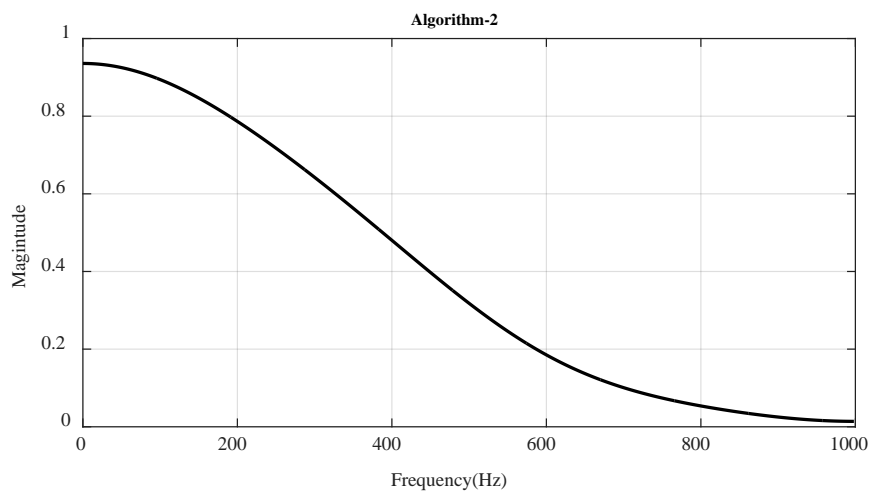

Figure 3. An FIR filter that the desired frequency response $(H(k)$ characteristics for Algorithm-2. 

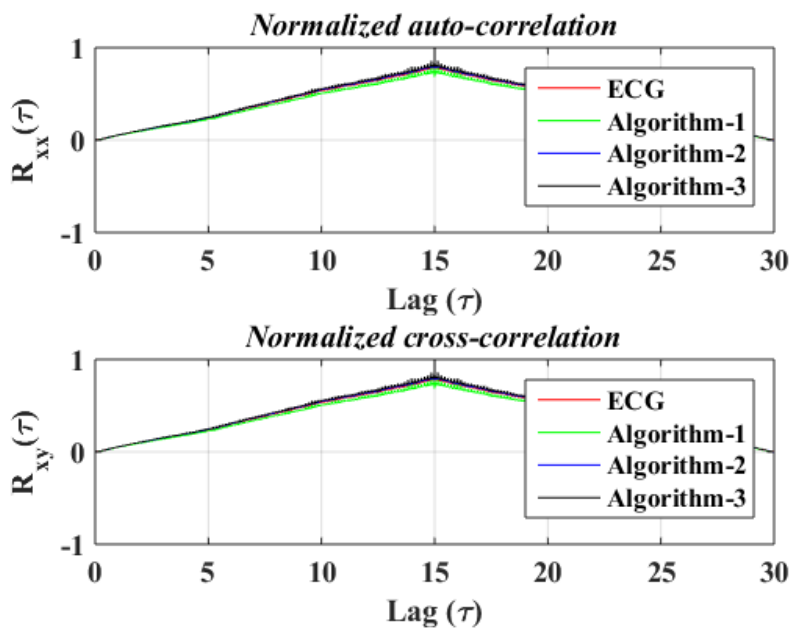

Figure 4. Correlation of ECG signal and filtered signal by auto correlation $\left(R_{x x}(\tau)\right)$ and cross correlation $\left(\boldsymbol{R}_{x y}(\tau)\right)$.

For comparison between the ECG signal and filtered signal by proposed algorithm, we have also considered three processes such autocorrelation, cross-correlation and power spectral density (PSD) as described in section IV. In Figure 4, the first subplot indicates that the ECG signal and filtered signal by Algorithm-1, Algorithm-2 and Algorithm-3 with high peaks are good correlated individual by autocorrelation. This shows that the autocorrelation is a periodic function. The second subplot is shown while the high peak shown in filtered signal is present in the ECG signal by cross correlation. This is same as first subplot because autocorrelation and cross-correlation are maintains same properties in some cases.

To estimate of power spectral density of noisy or filtered signal, we have considered non-parametric methods such as Periodogram, Welch and Lomb-Scargle algorithm. Lomb-Scargle algorithm can compute spectra of nonuniformly sampled signals or signals with missing samples. This algorithm is used to find out noninformity of ECG signal of MIT-BIH database. In Figure 5 we can be observed all signals are uniformly collected of ECG signal. We have used for test by $50 \mathrm{~Hz}$ in the noisy signal into ECG signal whereas sampled frequency of each signal $2000 \mathrm{~Hz}$ and then estimate power spectral density by Periodogram, and Welch methods. In Figure 5 it can observed that peak of noisy signal is raised because it's added by noise and the larger the amplitude for a given power. The filter signal by Algorithm 1, 2 \& 3 have smaller amplitude of power than noisy ECG signal and more and more resolution of side lobes of filtered signal.

The performance parameters for detection have used accuracy, sensitivity, specificity, precision, [20]. These parameters are defined as follows:

$$
\begin{gathered}
\text { Accuracy }=\frac{\text { Total no. of correctly detected sample points }}{\text { Total numbers of sample points }} \times 100 \\
\text { Sensitivity }=\frac{\text { True Positive }}{\text { True Positive }+ \text { Fasle Negative }} \times 100
\end{gathered}
$$




$$
\text { Specificity }=\frac{\text { True Negative }}{\text { True Negative }+ \text { Fasle Positive }} \times 100
$$

\section{Precision $=\frac{\text { True Positive }}{\text { True Positive }+ \text { Fasle Positive }} \times 100$}

Table 5: Comparisons of performance parameters for detection algorithms.

\begin{tabular}{|c|c|c|c|c|c|}
\hline Algorithm & Database & Accuracy (\%) & Sensitivity (\%) & Specificity (\%) & Precision (\%) \\
\hline N. Arzeno 2008 [10] & MIT-BIH & - & 99.68 & - & 99.63 \\
\hline V. Afonso 1999 [1]] & MIT-BIH & - & 99.59 & - & 99.56 \\
\hline J. Pan 1985 [3] & MIT-BIH & - & 99.30 & - & - \\
\hline P. Hamilton 1986 [13] & MIT-BIH & - & 99.69 & - & 99.77 \\
\hline J. Martinez 2004 [14] & MIT-BIH, QT, ST-T, CSE & - & 99.66 & - & 99.56 \\
\hline C. Li 1995 [15] & MIT-BIH & - & 99.80 & - & - \\
\hline B. Abibullaev 2011 [16] & MIT-BIH & - & 97.20 & - & 98.52 \\
\hline Q. Xue 1992 [17] & MIT-BIH & - & 99.50 & - & 97.50 \\
\hline D. Coast 1990 [18] & AHA & - & 97.25 & - & 85.67 \\
\hline R. Poli 1995 [19] & MIT-BIH & - & 99.60 & - & 99.51 \\
\hline A. Martinez 2010 [20] & MIT-BIH, QT, ST-T,TWA & - & 99.81 & - & 99.89 \\
\hline Proposed & MIT-BIH & 98.94 & 99.84 & 98.85 & 99.62 \\
\hline
\end{tabular}

We also observed the difference between the ECG noisy signal and filtered signal by Spectrogram. The spectrogram shows visual representation of spectrum of frequency in signal as they vary with time. The ECG signal is applied to short time Fourier transform by eight segment with Hamming window of length 512,256 samples that of each of segment overlaps with $2000 \mathrm{~Hz}$ sampling frequency. The Figure 6 shows of a signal in which the vertical axis is frequency, the horizontal axis is time, and amplitude is shown on a color map. This map shows the amount of energy of ECG signal is displayed as level of yellow color at time and frequency where weak energy appears blue color in the spectrogram. The Algorithm-2 \& 3 have shown high amount of energy ECG signal as yellow and also clearly show blue color which indicates the remove noise from ECG as compare with top Figure 6.

Many researcher have done some sate of the art noise remove algorithms. We did some research contribution in this field as comparison in our proposed noise removed algorithms as in Table V. This table shows that the proposed algorithms are the highest results than other reference works. The results are shown in average of SNR, PRD, MSE, Correlation coefficients values because each signal of MIT-BIH database is simulated and figure out in average of all signals for comparisons. 


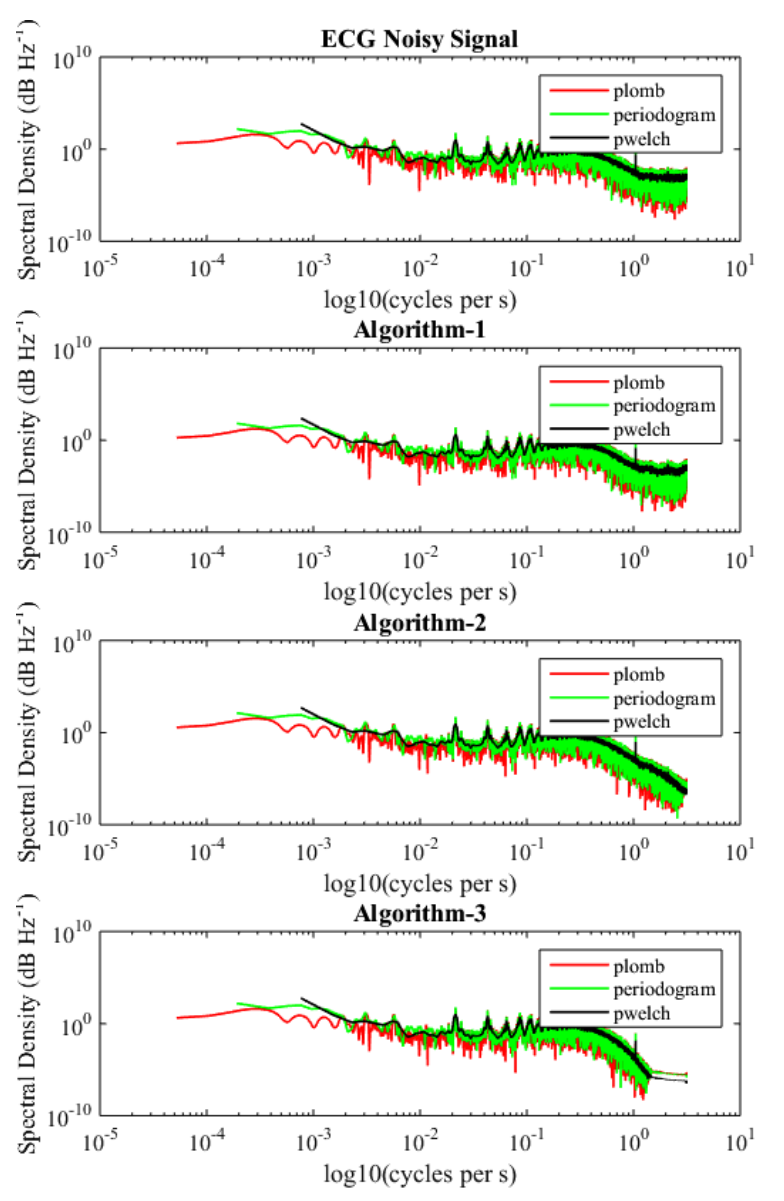

Figure 5. Power spectral density of ECG signal and filtered signal by Periodogram, Welch method and Lomb-Scargle algorithm.
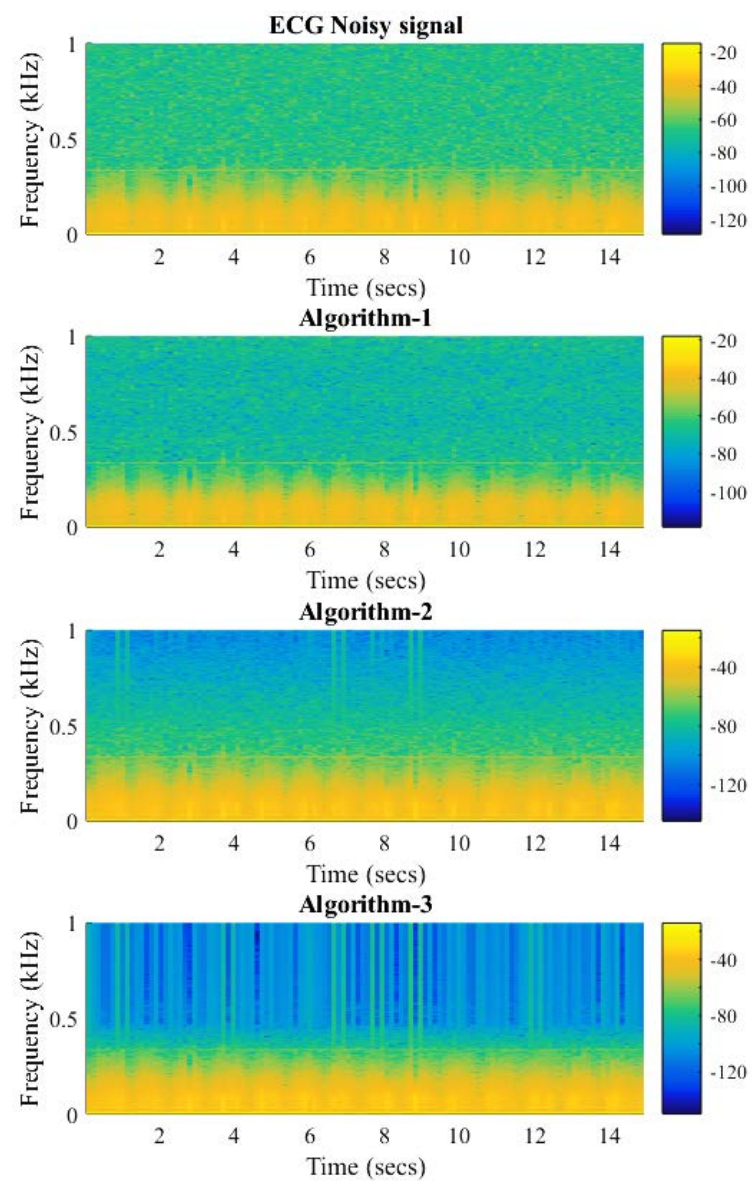

Figure 6. Spectrogram of noisy ECG and filtered ECG signal by proposed algorithms

After filtered ECG signal we can detect QRS complex of ECG signal by using Algorithm-4. Figure 7 shows QRS detection for the full sample indexes that was given in MIT-BIH database and Figure 6, its small scale sample indexes. The ECG signal and filtered ECG signal by Algorithm-1 as shown in Figure 7 (a) \& (b) and also Figure 8 (a) \& (b). The ECG signal obtained after the thresholding is shown in Figure 7 (c) \& 8 (c). Finally we have successfully detected the QRS complexes in ECG signal which are shown in Figure 7 (d) \& 8 (d). We also present a comparison of results obtained with the algorithms implemented as Table VI. The values presented are the results we got after doing multiple tests with each algorithm, and testing different detection parameters. We can get better results in accuracy, sensitivity, specificity, precision parameters than others with the entire database. For example, in Hamilton \& Tompkins or Pan \& Tompkins algorithm, have shown good detection rate but they don't find smaller peak in fixed interval. This algorithm would good sensitivity if local smaller peak would be detected by low interval, however the predictivity or precision would be worse. The proposed detection Algorithm-4 has acquired the values of detection parameter such as $98.94 \%$ accuracy, $99.84 \%$ sensitivity, $98.85 \%$ specificity, $98.62 \%$ precision. We also measured the heart rate which is 74.4828 . It proved that our algorithm is simulated properly. 

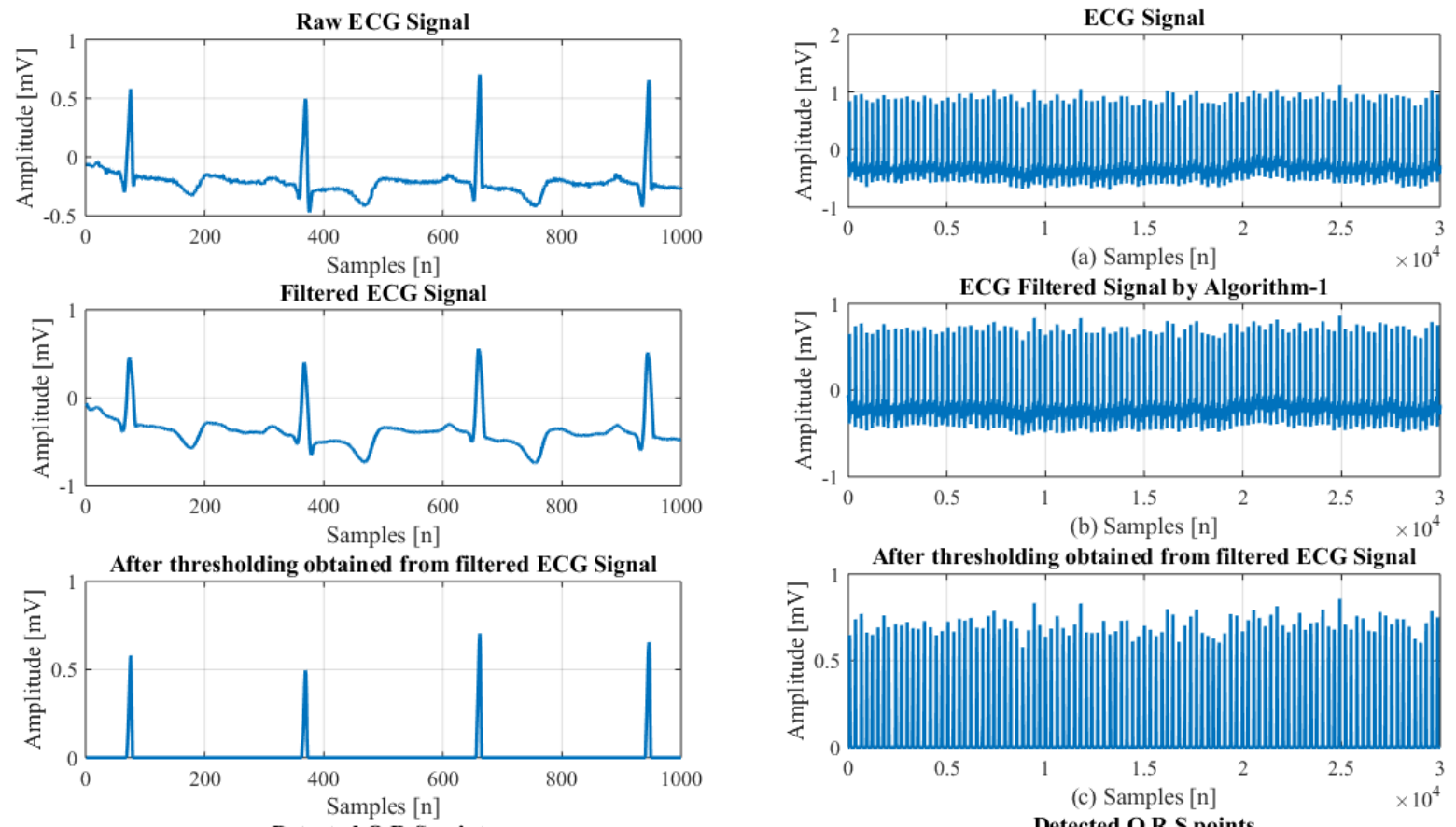

Detected Q R S points
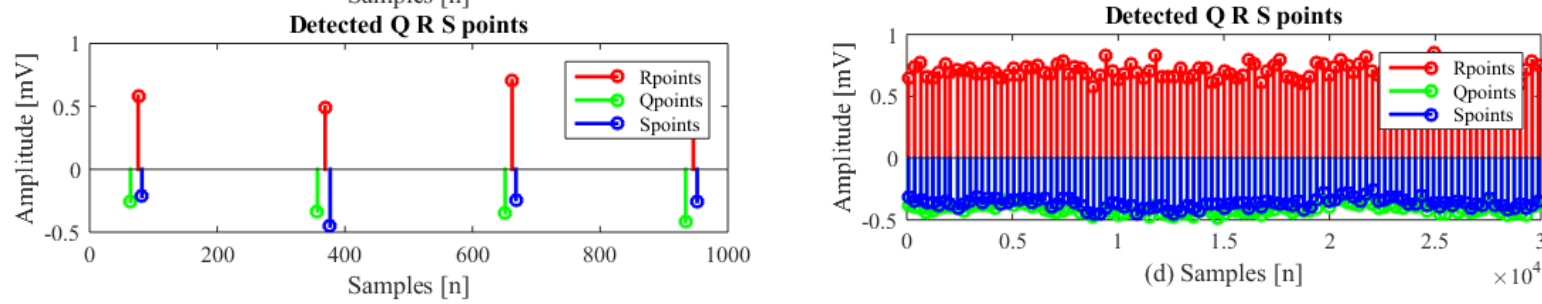

Figure 7. The detected QRS complexes in ECG signal (small sample indexes [n]).

Figure 8. The detected QRS complexes in ECG signal (Full sample indexes [n]).

\section{Conclusions}

We have successfully filtered ECG signal and also detected the QRS complex in ECG signal. The results shows higher signal-to-noise ratio, good PRD, low MSE and also positive correlation values which represent strong correlation between ECG signal and filtered signal. The simulation results have shown that proposed Algorithm 1, 2, and 3 are better for diagnostics purposes of ECG and Algorithm 4 is more efficient for detection of heart diseases. The proposed detection achieved higher accuracy, sensitivity, specificity and precision value than other conventional methods. The heart beat rate will be measured accurately and $100 \%$ accuracy from the detected QRS complexes by proposed detection algorithm and also specified the heart diseases based on database. 


\section{REFERENCES}

[1] Falco Strasser1, MichaelMuma2 and Abdelhak M. Zoubir ,"Motion Artifact Removal in ECG Signals using MultiResolution Thresholding", 20th European signal processing conference (EUSIPCO2011), Bucharest, Romania, August 27-31,2012.

[2] Mohamed Elgendi, Mirjam Jonkman, Friso De Boer," Improved QRS Detection Algorithm using Dynamic Thresholds", International Journal of Hybrid Information Technology, Vol. 2, No. 1, January, 2009.

[3] J. Pan and W. J. Tompkins, "A real-time QRS detection algorithm”, IEEE Transactions on Biomedical Engineering, vol. BME-32, 1985.

[4] Ren-Guey Lee, I-Chi Chou, Chien-Chih Lai, Ming-Hsiu Liu, Ming-Jang Chiu, "A Novel QRS Detection Algorithm Applied To The Analysis For Heart Rate Variability Of Patients With Sleep Apnea” ,Biomedical Engineering applications, Basis \& Communications, Vol. 17, No. 5 October 2005..

[5] Q. Xue, Y. H. Hu, and W. J. Tompkins, "Neural-network-based adaptive matched filtering for QRS detection", IEEE Transaction Biomedical Engineering, 1992, 317-329.

[6] V.S. Chouhan and S.S. Mehta, "Detection of QRS complexes in 12-lead ECG using adaptive quantized threshold" International Journal of Computer Science and Network Security, Vol. 8, No.1, pp. 155-163, 2008.

[7] MIT-BIH Arrhythmia Database, www.physionet.org.

[8] G. M. Friesen, T. C. Jannett, M. A. Jadallah, S. L. Yates, S. R. Quint, and H. T. Nagle, "A comparison of the noise sensitivity of nine QRS detection algorithms", IEEE Transactions on Biomedical Engineering, vol. 37, pp. 85-98, 1990.

[9] Emmanuel Ifeachor. and Barrie WQ. Jervis, "Digital Signal Processing: A Practical Approach, 2/E" Publisher: Pearson Education India, 2002, ISBN 813708241, 9788131708248.

[10] N. Arzeno, Z. D. Deng, and C. S. Poon, "Analysis of first-derivative based QRS detection algorithms", IEEE Transactions on Biomedical Engineering, vol. 55, no. 2, pp. 478-484, 2008.

[11] V. Afonso, W. J. Tompkins, T. Nguyen, and S. Luo, "ECG beat detection using filter banks", IEEE Transactions on Biomedical Engineering, Vol. 46, No. 2, pp. 192-202, 1999.

[12] P. S. Hamilton and W. J. Tompkins, "Quantitative investigation of QRS detection rules using the MIT/BIH arrhythmia database", IEEE Transactions on Biomedical Engineering, vol. BME-33, no. 12, pp.1157-1165, 1986.

[13] J. Martinez, R. Almeida, S. Olmos, A. Rocha, and P. Laguna, "A wavelet based ECG delineator: evaluation on standard databases", IEEE Transactions on Biomedical Engineering, vol. 51, no. 4, pp. 570-581, 2004.

[14] C. Li, C. Zheng, and C. Tai, "Detection of ECG characteristic points using wavelet transforms", IEEE Transactions on Biomedical Engineering, vol. 42, no. 1, pp. 21-28, 1995.

[15] B. Abibullaev and H. Seo, "A new QRS detection method using wavelets and artificial neural networks", Journal of Medical Systems, vol. 35, no. 4,pp. 683-691, 2011. 
Jannatul Robaiat Mou, Sheikh Md. Rabiul Islam, Xu Huang and Keng Liang Ou; Noise Removal and QRS Detection of ECG Signal. Journal of Biomedical Engineering and Medical Imaging, Volume 3, No 4, August (2016), pp 1-17

[16] Q. Xue, Y. Hu, and W. J. Tompkins, "Neural-network-based adaptive matched filtering for QRS detection", Biomedical Engineering, IEEE Transactions on, vol. 39, no. 4, pp. 317-329, 1992.

[17] D. Coast, R. Stern, G. Cano, and S. Briller, \An approach to cardiac arrhythmia analysis using hidden markov models," IEEE Transactions on Biomedical Engineering, , vol. 37, no. 9, pp. 826-836, 1990.

[18] R. Poli, S. Cagnoni, and G. Valli, "Genetic design of optimum linear and nonlinear QRS detectors", IEEE Transactions on Biomedical Engineering, vol. 42, no. 11, pp. 1137-1141, 1995.

[19] A. Martinez, R. Alcaraz, and J. J. Rieta, "Application of the phasor transform for automatic delineation of singlelead ECG fiducial points," Physiological Measurement, vol. 31, no. 11, pp. 1467-1485, 2010.

[20] Hafeez Ullah Amin, Aamir Saeed Malik, Rana Fayyaz Ahmad, Nasreen Badruddin, Nidal Kamel, Muhammad Hussain, Weng-TinkChooi "Feature extraction and classification for EEG signals using wavelet transform and machine learning techniques" Australasian Physical \& Engineering Sciences in Medicine, Volume 38, Issue 1, pp 139-149, March 2015.

[21] U. Biswas, A. Das, S. Debnath and I. Oishee, "ECG signal denoising by using least-mean-square and normalisedleast-mean-square algorithm based adaptive filter," Informatics, Electronics \& Vision (ICIEV), 2014

[22] Sheikh Md. Rabiul Islam, Xu Huang, and Dharmendra Sharma, "Wavelet Based Denoising Algorithm of the ECG Signal Corrupted by WGN and Poisson Noise," in 2012 International Symposium on Communications and Information Technologies (ISCIT), pp. 165-168, 2012.

[23] A. D. Jeyarani, T. Jaya Singh, “ Analysis of noise reduction techniques on QRS ECG waveform - by applying different filters", Recent Advances in Space Technology Services and Climate Change (RSTSCC), 2010, pp. 149 -152 , Nov. 2010.

[24] Yong Lian and Poh Choo Ho, "ECG noise reduction using multiplier-free FIR digital filters," S2004 7th International Conference on Signal Processing, 2004. Proceedings. ICSP '04, 2004, vol. 3, pp. 2198-2201.

[25] Alina Mirza, S. Mehak Kabir, Sara Ayub, Shahzad Amin sheikh, "Impulsive Noise Cancellation of ECG signal based on SSRLS", Proceedings of the 2015 International Conference on Soft Computing and Software Engineering (SCSE'15), Vol. 62, pp. 196-202, 2015.

[26] M. Butt, N. Razzaq, I. Sadiq, M. Salman and T. Zaidi, "Power Line Interference removal from ECG signal using SSRLS algorithm," 2013 IEEE 9th International Colloquium on Signal Processing and its Applications (CSPA), , Kuala Lumpur, pp. 95-98, 2013.

[27] Monson H. Hayes "Statistical Digital Signal Processing and Modeling", John Wiley \& Sons, Inc. ISBN: 978-0-47159431-4 
Journal of Biomedical Engineering and Medical Imaging, Volume 3, No. 4, Aug 2016

Table 1: Results of performance parameter correlation coefficients for proposed algorithms

\begin{tabular}{|c|c|c|c|c|c|c|c|c|c|c|c|c|c|c|c|}
\hline \multirow[t]{2}{*}{ Noises } & \multirow{2}{*}{$\begin{array}{l}\text { Proposed } \\
\text { method }\end{array}$} & \multicolumn{14}{|c|}{ Correlation } \\
\hline & & $\begin{array}{c}\text { Patient } \\
\text { Data } \\
100 \\
\end{array}$ & $\begin{array}{l}\text { Patient } \\
\text { Data } \\
105 \\
\end{array}$ & $\begin{array}{c}\text { Patient } \\
\text { Data } \\
107 \\
\end{array}$ & $\begin{array}{c}\text { Patient } \\
\text { Data } \\
108 \\
\end{array}$ & $\begin{array}{c}\text { Patient } \\
\text { Data } \\
109 \\
\end{array}$ & $\begin{array}{c}\text { Patient } \\
\text { Data } \\
111 \\
\end{array}$ & $\begin{array}{c}\text { Patient } \\
\text { Data } \\
112 \\
\end{array}$ & $\begin{array}{c}\text { Patient } \\
\text { Data } \\
113 \\
\end{array}$ & $\begin{array}{c}\text { Patient } \\
\text { Data } \\
114 \\
\end{array}$ & $\begin{array}{c}\text { Patient } \\
\text { Data } \\
115 \\
\end{array}$ & $\begin{array}{c}\text { Patient } \\
\text { Data } \\
119 \\
\end{array}$ & $\begin{array}{c}\text { Patient } \\
\text { Data } \\
200 \\
\end{array}$ & \begin{tabular}{|l} 
Patient \\
Data \\
213 \\
\end{tabular} & verage \\
\hline \multirow{3}{*}{$\begin{array}{l}\text { Power line } \\
\text { interference }\end{array}$} & $\mathrm{m}-1$ & 0.9810 & 0.9930 & 0.9985 & 0.9814 & 0.9960 & 0.9855 & 0.9864 & 0.9934 & 0.9917 & 0.9924 & 0.9964 & 0.9947 & 0.9953 & 9912 \\
\hline & Algorithm-2 & 0.3638 & 0.8068 & 0.9171 & 0.8858 & 0.8710 & 0.8177 & 0.7652 & 0.7165 & 0.7202 & .5725 & .8474 & 0.8342 & .6568 & 0.7519 \\
\hline & Algorit & 1204 & 0.6670 & 0 & 3 & 0.7670 & 0.7168 & 6373 & 6028 & 5649 & 4145 & 7600 & 7329 & 4490 & 6252 \\
\hline \multirow{3}{*}{$\begin{array}{l}\text { Base line } \\
\text { wander }\end{array}$} & Algorithm-1 & 0.9810 & 0.9930 & 8.9356 & 0.9814 & 0.9960 & 0.9855 & 0.9864 & 0.9934 & 0.9917 & 0.9924 & 0.9964 & 0.9947 & 0.9953 & 0.9912 \\
\hline & Algorithm-2 & 0.3638 & 0.8068 & 6.7400 & 0.8858 & 0.8710 & 0.8177 & 0.7652 & 0.7165 & 0.7202 & 0.5725 & 0.8474 & 0.8342 & 0.6568 & 0.7519 \\
\hline & Algorithm-3 & 0.1204 & 0.6678 & 3.8591 & 0.8353 & 0.7670 & 0.7168 & 0.6373 & 0.6028 & 0.5649 & 0.4145 & 0.7600 & 0.7329 & 0.4490 & 0.6252 \\
\hline \multirow[t]{3}{*}{ EMG } & Algorithm-1 & 0.9920 & 0.9934 & 0.9977 & 0.9934 & 0.9975 & 0.9942 & 0.9969 & 0.9929 & 0.9901 & 0.9913 & 0.9957 & 0.9945 & .9952 & 0.9942 \\
\hline & Algorithm-2 & 0.3724 & 0.81054 & 0.9175 & 0.8989 & 0.8738 & 0.8300 & 0.7729 & 0.7193 & 0.7236 & 0.5715 & 0.8487 & 0.8366 & 0.6583 & 0.7564 \\
\hline & Algorithm-3 & 0.1249 & 0.6708 & 0.8610 & 0.8464 & 0.7699 & 0.7296 & 0.6422 & 0.6059 & 0.5678 & 0.4121 & 0.7613 & 0.7351 & 0.4506 & 0.6290 \\
\hline \multirow[t]{3}{*}{ orupt } & Algorithm-1 & 0.9540 & 0.9822 & 0.9968 & 0.9452 & 0.9901 & 0.9658 & 0.9648 & 0.9884 & 0.9804 & 0.9840 & 0.9929 & 0.9883 & 0.9922 & 0.9788 \\
\hline & Algorithm-2 & 0.3496 & 0.7968 & 0.9156 & 0.8490 & 0.8655 & 0.8026 & 0.7448 & 0.7136 & 0.7090 & 0.5634 & 0.8442 & 0.8290 & 0.6544 & 0.7413 \\
\hline & lgorithm-3 & 1151 & 0.6588 & 0.8590 & 0.7984 & 0.7623 & 0.7056 & 0.6185 & 0.6012 & 0.5549 & 0.4053 & 0.7570 & 0.7290 & 0.4447 & 0.6161 \\
\hline
\end{tabular}

Table 2: Results of performance parameter SNR for proposed algorithms

\begin{tabular}{|c|c|c|c|c|c|c|c|c|c|c|c|c|c|c|c|}
\hline \multirow[t]{2}{*}{ Noises } & \multirow{2}{*}{$\begin{array}{c}\text { Proposed } \\
\text { method }\end{array}$} & \multicolumn{14}{|c|}{ SNR(dB) } \\
\hline & & $\begin{array}{c}\text { Patient } \\
\text { Data } \\
\mathbf{1 0 0}\end{array}$ & $\begin{array}{c}\text { Patient } \\
\text { Data } \\
\mathbf{1 0 5}\end{array}$ & $\begin{array}{c}\text { Patient } \\
\text { Data } \\
107\end{array}$ & $\begin{array}{c}\text { Patient } \\
\text { Data } \\
108\end{array}$ & $\begin{array}{c}\text { Patient } \\
\text { Data } \\
109\end{array}$ & $\begin{array}{c}\text { Patient } \\
\text { Data } \\
111\end{array}$ & $\begin{array}{c}\text { Patient } \\
\text { Data } \\
112\end{array}$ & $\begin{array}{c}\text { Patient } \\
\text { Data } \\
113\end{array}$ & $\begin{array}{c}\text { Patient } \\
\text { Data } \\
\mathbf{1 1 4}\end{array}$ & $\begin{array}{c}\text { Patient } \\
\text { Data } \\
\mathbf{1 1 5}\end{array}$ & $\begin{array}{c}\text { Patient } \\
\text { Data } \\
\mathbf{1 1 9}\end{array}$ & $\begin{array}{c}\text { Patient } \\
\text { Data } \\
200\end{array}$ & $\begin{array}{c}\text { Patient } \\
\text { Data } \\
\mathbf{2 1 3}\end{array}$ & Average \\
\hline \multirow{3}{*}{$\begin{array}{c}\text { Power line } \\
\text { interference }\end{array}$} & Algorithm-1 & 8.7026 & 9.1272 & 8.9356 & 8.3570 & 8.9165 & 8.2043 & 8.3779 & 9.5803 & 10.127 & 9.0088 & 8.6046 & 9.2429 & 10.080 & 9.0202 \\
\hline & Algorithm-2 & 2.4704 & 0.7136 & 6.7400 & 13.269 & 5.6414 & 4.2531 & 31.117 & 2.1884 & 1.9574 & 4.1981 & 11.178 & 3.6151 & 0.6044 & 6.7659 \\
\hline & Algorithm-3 & 2.6492 & 2.2206 & 3.8591 & 8.9758 & 3.0001 & 2.6274 & 21.830 & 1.4913 & 1.1951 & 2.9669 & 7.0101 & 2.1375 & 1.3177 & 4.7139 \\
\hline \multirow{3}{*}{$\begin{array}{l}\text { Base line } \\
\text { wander }\end{array}$} & Algorithm-1 & 8.7026 & 9.1272 & 8.9356 & 8.3570 & 8.9165 & 8.2043 & 8.3779 & 9.5803 & 10.127 & 9.0088 & 8.6046 & 9.2429 & 10.080 & 9.0203 \\
\hline & Algorithm-2 & 3.7404 & 4.0055 & 6.7400 & 13.269 & 5.6414 & 4.2531 & 31.117 & 2.1884 & 1.9574 & 4.1981 & 11.178 & 3.6151 & 2.2164 & 7.2399 \\
\hline & Algorithm-3 & 2.6492 & 2.2206 & 3.8591 & 8.9758 & 3.0001 & 2.6274 & 21.830 & 1.4913 & 1.1951 & 2.9669 & 7.0101 & 2.1375 & 1.3177 & 4.7139 \\
\hline \multirow[t]{3}{*}{ EMG } & Algorithm-1 & 9.1219 & 9.2139 & 8.9343 & 8.9343 & 8.5108 & 9.1113 & 9.0484 & 8.4828 & 9.7150 & 9.0115 & 8.6637 & 9.2509 & 10.196 & 9.0919 \\
\hline & Algorithm-2 & 3.8660 & 4.1099 & 6.7775 & 6.7775 & 15.493 & 5.7796 & 4.5655 & 32.829 & 2.2094 & 4.2385 & 11.298 & 3.6821 & 2.2270 & 7.9886 \\
\hline & Algorithm-3 & 2.7110 & 2.2606 & 3.8740 & 3.8740 & 10.224 & 3.0434 & 2.7491 & 22.666 & 1.5020 & 2.9936 & 7.0517 & 2.1665 & 1.3216 & 5.1105 \\
\hline \multirow[t]{3}{*}{ Abrupt } & Algorithm-1 & 8.3868 & 8.6422 & 8.8308 & 7.6200 & 8.7393 & 7.8343 & 8.3691 & 9.4755 & 8.9096 & 8.8588 & 8.6039 & 9.1075 & 9.9620 & 8.7184 \\
\hline & Algorithm-2 & 3.5721 & 3.7972 & 6.6281 & 10.168 & 5.4117 & 3.8347 & 28.967 & 2.1480 & 1.8703 & 4.1219 & 10.978 & 3.4783 & 2.1964 & 6.7055 \\
\hline & Algorithm-3 & 2.5436 & 2.1445 & 3.8166 & 7.2470 & 2.9190 & 2.4215 & 20.423 & 1.4673 & 1.1585 & 2.9224 & 6.9055 & 2.0747 & 1.3087 & 4.4117 \\
\hline
\end{tabular}

Table 3: Results of performance parameter MSE for proposed algorithms

\begin{tabular}{|c|c|c|c|c|c|c|c|c|c|c|c|c|c|c|c|}
\hline \multirow[t]{2}{*}{ Noises } & \multirow{2}{*}{$\begin{array}{r}\text { Proposed } \\
\text { method }\end{array}$} & \multicolumn{14}{|c|}{ MSE } \\
\hline & & \begin{tabular}{|c} 
Patient \\
Data \\
100
\end{tabular} & $\begin{array}{c}\text { Patient } \\
\text { Data } \\
105\end{array}$ & $\begin{array}{c}\text { Patient } \\
\text { Data } \\
107\end{array}$ & $\begin{array}{c}\text { Patient } \\
\text { Data } \\
108\end{array}$ & $\begin{array}{c}\text { Patient } \\
\text { Data } \\
109\end{array}$ & $\begin{array}{c}\text { Patient } \\
\text { Data } \\
111\end{array}$ & $\begin{array}{c}\text { Patient } \\
\text { Data } \\
112\end{array}$ & $\begin{array}{c}\text { Patient } \\
\text { Data } \\
113\end{array}$ & $\begin{array}{c}\text { Patient } \\
\text { Data } \\
114\end{array}$ & $\begin{array}{c}\text { Patient } \\
\text { Data } \\
115\end{array}$ & $\begin{array}{c}\text { Patient } \\
\text { Data } \\
119\end{array}$ & $\begin{array}{c}\text { Patient } \\
\text { Data } \\
200\end{array}$ & \begin{tabular}{|c} 
Patient \\
Data \\
213
\end{tabular} & Average \\
\hline \multirow{3}{*}{$\begin{array}{l}\text { Power line } \\
\text { interference }\end{array}$} & Algorithm-1 & 0.0160 & 0.0156 & 0.0810 & 0.0107 & 0.0280 & 0.0085 & 0.0889 & 0.0224 & 0.0090 & 0.0477 & 0.1223 & 0.0188 & 0.0448 & 0.0395 \\
\hline & Algorithm-2 & 0.0371 & 0.0355 & 0.1074 & 0.0067 & 0.0443 & 0.0165 & 0.0239 & 0.0979 & 0.0467 & 0.1024 & 0.0941 & 0.0482 & 0.0247 & 0.0527 \\
\hline & Algorithm-3 & 0.0525 & 0.0641 & 0.1876 & 0.0099 & 0.0833 & 0.0267 & 0.0341 & 0.1436 & 0.0764 & 0.1448 & 0.1501 & 0.0815 & 0.0342 & 0.0837 \\
\hline \multirow{3}{*}{$\begin{array}{l}\text { Base line } \\
\text { wander }\end{array}$} & Algorithm-1 & 0.0160 & 0.0156 & 0.0810 & 0.0107 & 0.0280 & 0.0085 & 0.0889 & 0.0224 & 0.0090 & 0.0477 & 0.1223 & 0.0188 & 0.0448 & 0.0395 \\
\hline & Algorithm-2 & 0.0371 & 0.0355 & 0.1074 & 0.0067 & 0.0443 & 0.0165 & 0.0239 & 0.0979 & 0.0467 & 0.1024 & 0.0941 & 0.0482 & 0.0247 & 0.0527 \\
\hline & Algorithm-3 & 0.0525 & 0.0641 & 0.1876 & 0.0099 & 0.0833 & 0.0267 & 0.0341 & 0.1436 & 0.0764 & 0.1448 & 0.1501 & 0.0815 & 0.0342 & 0.0837 \\
\hline \multirow[t]{3}{*}{ EMG } & Algorithm-1 & 0.0152 & 0.0154 & 0.0810 & 0.0105 & 0.0274 & 0.0077 & 0.0878 & 0.0220 & 0.0093 & 0.0477 & 0.1215 & 0.0188 & 0.0443 & 0.0391 \\
\hline & Algorithm-2 & 0.0360 & 0.0384 & 0.1068 & 0.0058 & 0.0433 & 0.0153 & 0.0227 & 0.0969 & 0.0459 & 0.1014 & 0.0931 & 0.0473 & 0.0202 & 0.0517 \\
\hline & Algorithm-3 & 0.0513 & 0.0629 & 0.1868 & 0.0087 & 0.0821 & 0.0255 & 0.0328 & 0.1426 & 0.0754 & 0.1435 & 0.1492 & 0.0804 & 0.0341 & 0.0827 \\
\hline \multirow[t]{3}{*}{ Abrupt } & Algorithm-1 & 0.0166 & 0.0150 & 0.0819 & 0.0117 & 0.0286 & 0.0089 & 0.0890 & 0.0226 & 0.0103 & 0.0485 & 0.1223 & 0.0191 & 0.0438 & 0.0398 \\
\hline & Algorithm-2 & 0.0389 & 0.0375 & 0.1092 & 0.0088 & 0.0462 & 0.0183 & 0.0257 & 0.0997 & 0.0488 & 0.1042 & 0.0959 & 0.0501 & 0.0246 & 0.0544 \\
\hline & Algorithm-3 & 0.0547 & 0.0629 & 0.1896 & 0.0123 & 0.0856 & 0.0289 & 0.0365 & 0.1460 & 0.0788 & 0.1470 & 0.1524 & 0.0839 & 0.0341 & 0.0855 \\
\hline
\end{tabular}


Jannatul Robaiat Mou, Sheikh Md. Rabiul Islam, Xu Huang and Keng Liang Ou; Noise Removal and QRS Detection of ECG Signal. Journal of Biomedical Engineering and Medical Imaging, Volume 3, No 4, August (2016), pp 1-17

Table 4: Results of performance parameter PRD for proposed algorithms

\begin{tabular}{|c|c|c|c|c|c|c|c|c|c|c|c|c|c|c|c|}
\hline \multirow[t]{2}{*}{ Noises } & \multirow{2}{*}{$\begin{array}{l}\text { Proposed } \\
\text { method }\end{array}$} & \multicolumn{14}{|c|}{ PRD\% } \\
\hline & & $\begin{array}{c}\text { Patient } \\
\text { Data } \\
100\end{array}$ & $\begin{array}{c}\text { Patient } \\
\text { Data } \\
105\end{array}$ & \begin{tabular}{|c|} 
Patient \\
Data \\
107
\end{tabular} & $\begin{array}{l}\text { Patient } \\
\text { Data } \\
108\end{array}$ & $\begin{array}{l}\text { Patient } \\
\text { Data } \\
109\end{array}$ & $\begin{array}{c}\text { Patient } \\
\text { Data } \\
111 \\
\end{array}$ & $\begin{array}{c}\text { Patient } \\
\text { Data } \\
112\end{array}$ & $\begin{array}{c}\text { Patient } \\
\text { Data } \\
113\end{array}$ & $\begin{array}{c}\text { Patient } \\
\text { Data } \\
114\end{array}$ & \begin{tabular}{|c|} 
Patient \\
Data \\
115
\end{tabular} & $\begin{array}{l}\text { Patient } \\
\text { Data } \\
119\end{array}$ & $\begin{array}{c}\text { Patient } \\
\text { Data } \\
200\end{array}$ & $\begin{array}{c}\text { Patient } \\
\text { Data } \\
213\end{array}$ & Average \\
\hline \multirow{3}{*}{$\begin{array}{c}\text { Power line } \\
\text { interference }\end{array}$} & Algorithm-1 & 41.41 & 40.24 & 40.94 & 42.47 & 40.93 & 42.82 & 42.6590 & 39.01 & 37.59 & 40.65 & 41.93 & 39.94 & 37.87 & 40.65 \\
\hline & Alsorithm-2 & 61.49 & 75.68 & 41.53 & 28.79 & 45.80 & 53.84 & 18.6852 & 80.98 & 86.71 & 54.09 & 31.70 & 58.93 & 60.32 & 53.73 \\
\hline & Alsorithm-3 & 68.60 & 76.29 & 54.60 & 34.09 & 63.33 & 68.97 & 21.6125 & 90.97 & 90.83 & 63.87 & 39.18 & 78.33 & 70.99 & 63.20 \\
\hline \multirow{3}{*}{$\begin{array}{l}\text { Base line } \\
\text { wander }\end{array}$} & Algorithm-1 & 41.41 & 40.24 & 40.94 & 42.47 & 40.93 & 42.82 & 42.6590 & 39.01 & 37.59 & 40.65 & 41.93 & 39.94 & 37.87 & 40.65 \\
\hline & Algorithm-2 & 61.49 & 55.48 & 41.53 & 28.79 & 45.80 & 53.84 & 18.6852 & 80.98 & 86.71 & 54.09 & 31.70 & 58.93 & 80.32 & 53.71 \\
\hline & Algorithm-3 & 68.60 & 76.29 & 54.60 & 34.09 & 63.33 & 68.97 & 21.6125 & 90.97 & 90.83 & 63.87 & 39.18 & 78.33 & 90.99 & 64.74 \\
\hline \multirow[t]{3}{*}{ EMG } & Algorithm-1 & 40.33 & 40.02 & 40.92 & 42.18 & 40.43 & 40.50 & 42.3583 & 38.65 & 38.11 & 40.63 & 41.74 & 39.92 & 37.61 & 40.26 \\
\hline & Alsorithm-2 & 56.77 & 54.65 & 41.39 & 26.71 & 45.17 & 51.56 & 18.1754 & 80.34 & 86.14 & 53.81 & 31.50 & 58.3 .8 & 79.83 & 52.64 \\
\hline & Algorithm-3 & 67.57 & 75.54 & 54.46 & 32.02 & 62.76 & 66.86 & 21.1913 & 91.24 & 90.26 & 63.56 & 39.02 & 77.78 & 86.56 & 63.75 \\
\hline \multirow[t]{3}{*}{ Abrupt } & Alsorithm-1 & 42.05 & 41.31 & 41.18 & 44.49 & 41.27 & 43.42 & 42.6242 & 39.08 & 40.18 & 40.97 & 41.89 & 40.06 & 38.06 & 41.27 \\
\hline & Alsorithm-2 & 59.04 & 56.92 & 41.87 & 32.91 & 46.67 & 56.09 & 19.3400 & 81.33 & 89.11 & 54.55 & 31.95 & 59.78 & 80.42 & 54.61 \\
\hline & Alsorithm-3 & 69.55 & 77.54 & 54.90 & 37.97 & 64.07 & 71.01 & 22.3136 & 92.22 & 93.44 & 64.31 & 39.43 & 79.06 & 89.55 & 65.79 \\
\hline
\end{tabular}

Table 5: Comparison results of existing methods, proposed algorithm and performance techniques for ECG dataset

\begin{tabular}{|c|c|c|c|c|c|c|c|}
\hline Ref. & Noises & $\begin{array}{c}\text { ECG databases } \\
\text { (MIT-BIH) }\end{array}$ & Methods & SNR & PRD (Average) & MSE (Average) & $\begin{array}{c}\text { Correlation } \\
\text { (Average) }\end{array}$ \\
\hline \multirow[t]{2}{*}{ [21] } & Base line wander & $\begin{array}{l}\text { Patient Data 100, } \\
\text { Patient Data 106, } \\
\text { Patient Data } 215\end{array}$ & $\begin{array}{l}\text { LMS } \\
\text { NLMS }\end{array}$ & $\begin{array}{l}\text { 3.4708(Average) } \\
\text { 3.8593(Average) }\end{array}$ & $\begin{array}{l}0.2034 \\
0.2034\end{array}$ & $\begin{array}{l}0.0653 \\
0.0652\end{array}$ & $x$ \\
\hline & Power line interference, & $\begin{array}{l}\text { Patient Data } 100, \\
\text { Patient Data } 106, \\
\text { Patient Data } 215\end{array}$ & $\begin{array}{l}\text { LMS } \\
\text { NLMS }\end{array}$ & $\begin{array}{l}\text { 7.5909(Average) } \\
7.0324 \text { (Average) }\end{array}$ & $\begin{array}{l}6.6319 \\
4.3414\end{array}$ & $\begin{array}{l}0.0311 \\
0.0310\end{array}$ & $x$ \\
\hline$[22]$ & WGN, Poisson & Patient Data 100 & Proposed Algorithm with DWT & $x$ & $x$ & $x$ & $x$ \\
\hline \multirow[t]{3}{*}{ [23] } & Power line interference & \multirow[t]{3}{*}{ Not given patient Data } & $\begin{array}{l}\text { Band stop filter } \\
\text { ( } 3 \text { order FIR filter) }\end{array}$ & $x$ & $x$ & $x$ & $x$ \\
\hline & Base line wander & & High Pass Filter & $\bar{x}$ & $x$ & $\bar{x}$ & $x$ \\
\hline & $\begin{array}{c}\text { Electromyography noise } \\
\text { (EMG noise) }\end{array}$ & & Low Pass Filter & $x$ & $x$ & $x$ & $x$ \\
\hline [24] & Power line interference & Not given patient Data & $\begin{array}{l}\text { linear phase digital } \\
\text { filter }\end{array}$ & $x$ & $x$ & $x$ & $x$ \\
\hline [25] & Impulsive noise & Not given patient Data. & $\begin{array}{l}\text { State Space Recursive Least } \\
\text { Square (SSRLS) algorithm }\end{array}$ & $x$ & $x$ & Below $20 \mathrm{~dB}$ & $x$ \\
\hline [26] & Power line interference & Not given patient Data. & $\begin{array}{l}\text { State Space Recursive Least } \\
\text { Square (SSRLS) algorithm }\end{array}$ & & & & \\
\hline \multirow{12}{*}{$\begin{array}{l}\text { Proposed } \\
\text { Algorithms }\end{array}$} & \multirow[t]{3}{*}{ Power line interference } & \multirow{12}{*}{$\begin{array}{l}\text { Patient Data 100, } \\
\text { Patient Data 105, } \\
\text { Patient Data 107, } \\
\text { Patient Data 108, } \\
\text { Patient Data 109, } \\
\text { Patient Data 111, } \\
\text { Patient Data 112, } \\
\text { Patient Data 113, } \\
\text { Patient Data } 114, \\
\text { Patient Data } 115 \\
\text { Patient Data } 119 \\
\text { Patient Data } 200 \\
\text { Patient Data } 213\end{array}$} & Algorithm-1 & 9.0202(Average) & $40.65 \%$ (Average) & 0.0395 (Average) & 0.9912 (Average) \\
\hline & & & Algortithm-2 & 6.7659(Average) & $53.73 \%$ (Average) & 0.0527 (Average) & 0.7519 (Average) \\
\hline & & & Algorithm-3 & 4.7139(Average) & $63.20 \%$ (Average) & 0.0837 (Average) & 0.6252 (Average) \\
\hline & \multirow[t]{3}{*}{ Base line wonder } & & Algorithm-1 & 9.0203(Average) & $40.65 \%$ (Average) & 0.0395 (Average) & 0.9912 (Average) \\
\hline & & & Algortithm-2 & 7.2399(Average) & 53.71\%(Average) & 0.0527 (Average) & 0.7519 (Average) \\
\hline & & & Algorithm-3 & 4.7139(Average) & 64.74\%(Average) & 0.0837 (Average) & 0.6252 (Average) \\
\hline & \multirow[t]{3}{*}{ EMG } & & Algorithm-1 & 9.0919(Average) & 40.26\%(Average) & 0.0391 (Average) & 0.9942 (Average) \\
\hline & & & Algortithm-2 & 7.9886(Average) & $52.64 \%$ (Average) & 0.0517 (Average) & 0.7564 (Average) \\
\hline & & & Algorithm-3 & 5.1105(Average) & 63.75\%(Average) & 0.0827 (Average) & 0.6290 (Average) \\
\hline & \multirow[t]{3}{*}{ Abrupt } & & Algorithm-1 & 8.7184(Average) & 41.27\%(Average) & 0.0398 (Average) & 0.9788 (Average) \\
\hline & & & Algortithm-2 & 6.7055(Average) & $54.61 \%$ (Average) & 0.0544 (Average) & 0.7413 (Average) \\
\hline & & & Algorithm-3 & 4.4117(Average) & $65.79 \%$ (Average) & 0.0855 (Average) & 0.6161 (Average) \\
\hline
\end{tabular}

U R L : http://dx.doi.org/10.14738/jbemi.34.2113 